RESEARCH ARTICLE

\title{
Evaluation of efficient transformation method for xylose reductase gene integration in Pichia pastoris GS115
}

\author{
Yamunasri P, Priyadharshini R and Sivakumar Uthandi* \\ *Biocatalysts laboratory, Department of Agricultural Microbiology, \\ Directorate of Natural Resource Management, Tamil Nadu Agricultural University, Coimbatore -641 003
}

\begin{abstract}
Pichia pastoris remains an amicable host for the expression of heterologous protein from eukaryotes. Achieving a high level of expression of yeast in the recombinant host has remained a challenge. Apart from the codon

preference of genes and proper protein folding for efficient expression of the heterologous gene, the main bottleneck is to efficiently integrate the heterologous gene into the host DNA. The present study evaluated the choice of available transformation methods such as lithium chloride, electroporation, and spheroplast for efficient integration of xylose reductase $(X r)$ gene of Candida tropicalis in P. pastoris. The results revealed that electro transformation was found to be an efficient method for the transformation for $x r$ in $P$. pastoris, yielding $1 \times 10^{6}$ transformants, followed by the lithium chloride method registering $2 \times 10^{3}$ transformants.
\end{abstract}

Received : 02 ${ }^{\text {nd }}$ November, 2020

Revised : $08^{\text {th }}$ December, 2020

Accepted : $24^{\text {th }}$ December, 2020

Keywords: Pichia pastoris; xylose reductase; Transformation.

\section{INTRODUCTION}

D-Xylose is metabolized in yeast via., oxidoreductase pathway requiring several enzymes and cofactors. Xylose reductase (XR) is the first enzyme that converts D-xylose to xylitol requiring $N A D(P) H$, followed by the conversion of D-xylitol to $D$-xylulose by xylitol dehydrogenase (XDH) and requires NAD(P)+. Xylitol kinase then converts D-xylulose to D-xylulose5-phosphate, which enters the pentose phosphate pathway (Jung et al., 2015). XR and XDH are critical enzymes in the pathway. Xylitol is an economically important compound and has many applications in the food and pharmaceutical industry (Mohamad et al., 2015). Since xylitol production from yeast is less expensive than chemical methods, many studies focused on the biological production of xylitol. Hence, cloning and integration of XR in yeast is vital in the production of xylitol. Introducing exogenous DNA (transformation) in yeast Saccharomyces cerevisiae was developed in 1978. Since then, many yeast and fungi have been successfully transformed with foreign DNA. There are chemical, physical, or enzymatic treatment methods for yeast transformation. A chemical methods employing lithium acetate or lithium chloride and PEG are well-known (Ito et al., 1983). Similarly, the electroporation method of transformation is the preferred physical method when compared to the chemical and biolistic, and glass bead method. Enzyme-based methods generate spheroplasts, which are then plated in regeneration agar to obtain transformants. The common methods for transforming $P$. pastoris are spheroplasting and PEG mediated transformations, lithium chloride mediated method, and electroporation. All method has its own advantages and disadvantages. These methods have two steps for the introduction of foreign DNA into Pichia cells; first is the preparation of competent yeast, and the second is the transformation of DNA into cells.

Previously we cloned and expressed $\mathrm{Xr}$ gene in PQE30Xa under the control of T7 promoter in E. coli M15 and used D-xylose and corncob during the fermentation for the production of xylitol in $E$. coli (Ariyan and Uthandi, 2019). Pichia pastoris, a methylotrophic yeast of ascomycetes class, is popularly used as a host to express heterologous proteins (Lin-Cereghino et al., 2005). This is due to its growth to high cell densities, increased protein production (intracellular and extracellular), controlled and robust regulation of promoters, and easy scale-up (Ahmad et al., 2014). Phillips Petroleum Company introduced $P$. pastoris, which utilizes methanol as a carbon source to produce single-cell protein as an additive to animal feed (Cregg et al., 1985). The commonly used expression systems for protein production in Pichia is GAP (Glyceraldehyde-3-phosphate dehydrogenase) and AOX1 (alcohol oxidase) promoters. AOX1 promoter is widely used for controlled expression in which the gene of interest is placed between 5'AOX and 3'AOX (Vogl and Glieder., 2013). AOX1 and AOX2 genes 
synthesize alcohol oxidase, which utilize methanol and convert it to formaldehyde and hydrogen peroxide. AOX1 is responsible for 90 percent of activity.

AOX1 gets induced only when methanol is added; until then, it remains in a repressed state. Expression of AOX1 genes and protein production is restricted or lowered due to the presence of carbon sources other than methanol at the time of induction. Due to this, the cells are grown first in glycerol medium to attain growth and are transferred to methanol medium for induction and expression (Cereghino and Cregg, 2000). P. pastoris transformants selection system used in this study is based on auxotrophic selection. The wild strain is a deficit of histidional dehydrogenase, and so the vectors with yeast his 4 gene is used to transform the foreign DNA. As a result, the mutant Pichia can grow in a histidine deficient environment. Transformation efficiency is comparatively low in $P$. pastoris than in other yeast. Hence we performed three preferred methods of transformation for $P$. pastoris in order to select the best method to obtain transformants in $P$. pastoris.

In this paper, lithium chloride mediated, electrophoration, and spheroplast methods were compared to transform P. pastoris GS115 with the $\mathrm{Xr}$ gene from Candida tropicalis cloned in vector pPIC3.5. The transformation protocol used, along with the results obtained for each method, is discussed.

\section{MATERIAL AND METHODS}

\section{Strains, vectors, and media:}

P. pastoris GS115 strain and vector pPIC3.5 were purchased from Invitrogen acquired by life technologies, USA (Catalog No. K1710-01). P. pastoris GS115 cells were grown in yeast extract peptone dextrose (YPD) broth (1\% yeast extract, $2 \%$ peptone, $2 \%$ dextrose). The transformed cells were grown in regeneration dextrose medium (RDB) or minimal dextrose medium (MD). The vector pPIC3.5 containing $C$. tropicals $X R$ gene $(C t X r)$ designated as pUSIXr was used (Fig 1). The plasmid was prepared using a plasmid DNA Kit (Thermo scientific Gene Jet plasmid miniprep kit, Ludhiana) followed by linearization with Sacl and purified using spin columns (Qiagen, Germany). The purified linear DNA was quantified in nano-drop (Thermo Scientific, USA).

\section{Spheroplasting method:}

The procedure used to generate spheroplast were followed according to the protocol mentioned in the Pichia Expression Kit. A single pure colony of $P$. pastoris GS115 from a fresh plate was inoculated as a starter into $5 \mathrm{~mL}$ YPD broth and incubated at $30{ }^{\circ} \mathrm{C}$ overnight under shaking conditions at 120 rpm. The overnight grown culture was used for spheroplast preparation. About $5 \mu \mathrm{L}$ of the overnight culture was used to inoculate $200 \mathrm{~mL}$ YPD broth grown in $500 \mathrm{~mL}$ conical flask. When the culture reached $\mathrm{OD}_{600}$ of 0.2 to 0.3 , the cells were harvested and washed in $20 \mathrm{~mL}$ of sterile water. The pellets were resuspended in SED solution (provided in the kit) (19 mL of SE $+1 \mathrm{~mL}$ of $1 \mathrm{M} \mathrm{DTT}$ ) and washed. About $20 \mathrm{~mL}$ of $1 \mathrm{M}$ sorbitol was used to wash cells. Finally, the cells were resuspended in $20 \mathrm{~mL}$ of SCE buffer (provided in the kit). About $10 \mathrm{~mL}$ of cells were used to determine the optimum time for spherolplasting by measuring OD at $800 \mathrm{~nm}$ in a multimode microplate reader (SpectraMax i3x, USA). Around $800 \mu \mathrm{L}$ of $5 \%$ SDS and $200 \mu \mathrm{L}$ of SCE were used as blank. The remaining cells were treated with zymolyase and incubated. The percentage of spheroplasting was calculated by using the formula time $t / O D$ of spheroplasting $=100-\left(O D_{800}\right.$ at time $\mathrm{t} / \mathrm{OD}_{800}$ at time 0) x 100

The second set of cells suspended in SCE buffer was added with $7.5 \mu \mathrm{L}$ of zymolyase and incubated for a time at which $70 \%$ speroplasting took place. After the optimum time, the cells were harvested by centrifugation at room temperature for $10 \mathrm{~min}$ at $750 \times g$. The spheroplast cells were washed with $10 \mathrm{~mL}$ of $1 \mathrm{M}$ sorbitol followed by $10 \mathrm{~mL}$ of CAS solution. Finally, the cells were suspended in $600 \mu \mathrm{L}$ of CAS (provided in the kit). Spheroplast cells (100 $\mu \mathrm{L}$ ) were taken in $2 \mathrm{~mL}$ of microfuge tubes, and 10 $\mu \mathrm{g}$ of linearized DNA was added to it and incubated at room temperature for $10 \mathrm{~min}$, followed by the addition of $1 \mathrm{~mL}$ PEG/CaT solution and incubated further for $10 \mathrm{~min}$ at room temperature. Transformed cells were obtained by centrifugation at $750 \mathrm{x}$ g for $10 \mathrm{~min}$, and the pellets were resuspended in $150 \mu \mathrm{L}$ SOS solution and incubated for $20 \mathrm{~min}$. About 850 $\mu \mathrm{L}$ of $1 \mathrm{M}$ sorbitol was added. From this, about 100 $\mu \mathrm{L}$ of cells were plated in RBD plates.

\section{Lithium chloride method:}

P. pastoris GS115 was grown in $50 \mathrm{~mL}$ of YPD to approximately an $O D_{600}$ of 1.0 . The cells were harvested by centrifugation at $1500 \times \mathrm{g}$ and washed with $20 \mathrm{~mL}$ of sterile water. Cell pellets were resuspended in $1 \mathrm{~mL}$ of $100 \mathrm{mM}$ lithium chloride and transferred to $1.5 \mathrm{~mL}$ microfuge tubes, and centrifuged at maximum speed for a few seconds. Supernatants were removed, and pellets were resuspended in $400 \mu \mathrm{L}$ of $100 \mathrm{mM} \mathrm{LiCl}_{2}$. About 50 $\mu \mathrm{L}$ of cells in lithium chloride suspension was used for single transformation. The cells were pelleted, and to that $240 \mu \mathrm{L}$ of $50 \%$ PEG4000, $36 \mu \mathrm{L}$ of $1 \mathrm{M}$ lithium chloride, $25 \mu \mathrm{L}$ of carrier DNA (Salmon sperm DNA), and pUSIXr ( $5 \mu \mathrm{g})$ were added and vortexed approximately for $1 \mathrm{~min}$. The tubes were incubated at $30{ }^{\circ} \mathrm{C}$ for $30 \mathrm{~min}$, and heat shock was given at 
$42{ }^{\circ} \mathrm{C}$ for $25 \mathrm{~min}$. Centrifugation was carried out at $8000 \mathrm{rpm}$, and the supernatant was removed. Pellets were resuspended in $1 \mathrm{~mL}$ of water, and from this, about $300 \mu \mathrm{L}$ was used for plating. Plates were incubated at $30^{\circ} \mathrm{C}$ for 2 days until the transformants appeared.

\section{Electrophoration method:}

A single pure colony of $P$. pastoris GS115 was inoculated into $5 \mathrm{~mL}$ YPD broth and incubated overnight at $30{ }^{\circ} \mathrm{C}$. Cells (1\%) was inoculated into $200 \mathrm{~mL}$ of YPD. At an $\mathrm{OD}_{600}$ of 1.3 to 1.5 , the cells were harvested and resuspended in $500 \mathrm{~mL}$ of ice-cold sterile water. Cells were centrifuged and resuspended in $20 \mathrm{~mL}$ of ice-cold sorbitol. Cells were again centrifuged and finally suspended in 1 $\mathrm{mL}$ of $1 \mathrm{M}$ sorbitol. About $50 \mu \mathrm{L}$ of competent cells were taken and mixed with $5 \mu \mathrm{g}$ of linearized DNA. The mixture was transferred to $0.2 \mathrm{~cm}$ ice-cold electroporation cuvette and incubated in ice for 2 to $5 \mathrm{~min}$. at $2000 \mathrm{kV}$ of pulse was passed for 4 millisec and immediately $1 \mathrm{~mL}$ of $1 \mathrm{M}$ ice-cold sorbitol was added. About 300 to $500 \mu \mathrm{L}$ of cells were used for plating and incubated for 4 to 6 days at $30{ }^{\circ} \mathrm{C}$.

\section{Screening of transformants:}

The cells following transformation were plated in RDB or MD plates along with appropriate controls. The spheroplast cells were mixed with top agar containing RDB or MD followed by plating onto bottom RDB or MD plate. The viability of cells prepared during transformation was confirmed in $\mathrm{RDBH}$ or $\mathrm{MDH}$. The transformed cells $\left(\sim 1 \times 10^{2}\right)$ were plated in RDB or MD plates after obtaining the transformants to confirm the growth, followed by colony PCR.

To confirm the presence of $X r$ gene in the transformants, selected colonies were subjected to colony PCR. Colonies from the plates were taken with a sterile toothpick, suspended in $10 \mu \mathrm{L}$ of sterile water, and boiled at $95{ }^{\circ} \mathrm{C}$ for $10 \mathrm{~min}$. The tubes were spun, and about $1 \mu \mathrm{L}$ was used for 10 $\mu L$ reaction. PCR reaction was performed using PCR Master Mix (Takara) with gene-specific xr primer and vector-specific Aox primers using the conditions of an initial denaturation at $94^{\circ} \mathrm{C}$ for 5 min followed by 28 cycles of denaturation at $94^{\circ} \mathrm{C}$, annealing at $55^{\circ} \mathrm{C}$, and extension at $72{ }^{\circ} \mathrm{C}$ followed by a final extension at $72^{\circ} \mathrm{C}$ for $5 \mathrm{~min}$. The PCR products were then run on $1 \%$ agarose gel to confirm the size of the product.

\section{RESULTS AND DISCUSSION}

\section{Spheroplasting method:}

In the present study, spheroplast was prepared by adding zymolyase to $P$. pastoris GS115. It was noticed that increasing the time of incubation after zymolyase addition increased the spheroplast generation. The concentration of $70 \%$ spheroplast generated was used for transformation with $10 \mu \mathrm{g}$ DNA. It was reported earlier that the transformation frequency increased when the concentration of spheroplasts was $3 \times 10^{7}-3 \times 10^{8}$. $\mathrm{mL}^{-1}$, and the amount of single-stranded DNA were $1-3 \mu \mathrm{g}$. The frequency dramatically decreased when the concentration of spheroplasts was $2 \times 10^{9} \cdot \mathrm{mL}^{-1}$, and the amount of DNA was $16 \mu \mathrm{g}$, indicating that the concentration of spheroplasts and amount of DNA were critical for high transformation frequency (Shigeyuki et al., 2010).

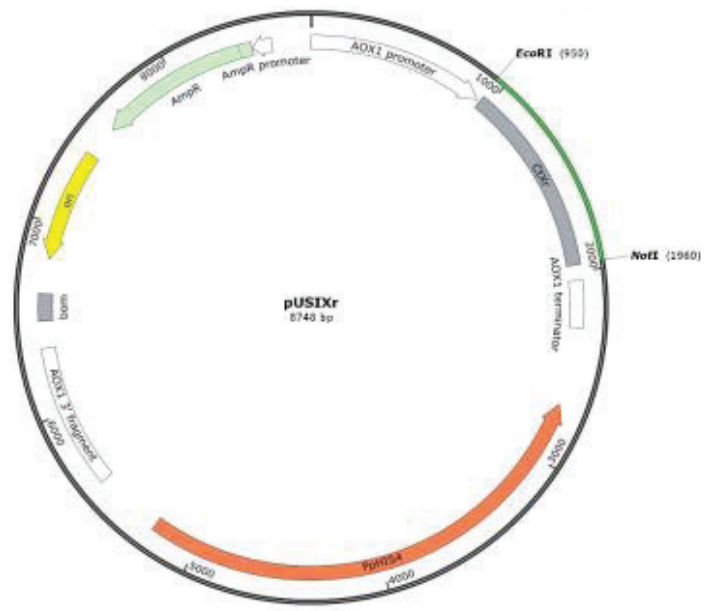

Figure 1. The map of cloned C. tropicalis $\mathrm{Xr}$ gene in pPIC3.5 plasmid (pUSIXr). The Xr gene was cloned in PPIC3.5 under the control of AOX promoter is indicated. The map was drawn using SnapGene software

After spheroplasting and transformation, the transformants were incubated at $28{ }^{\circ} \mathrm{C}$ and the transformants were observed on the second day of incubation. In our study, the spheroplast concentration of $70 \%$, which had $3 \times 10^{6}$ to $2 \times 10^{7}$ was used with the DNA concentration of $10 \mu \mathrm{g}$. The colonies were subsequently selected on RBD plates to confirm the presence of the integrant gene. After selection, it was observed that less than $1 \times 10^{1}$ to no colonies in the plate. Burgers and Percival (1987) proposed that decrease in efficiency of transformants may be due to high concentrations of lyticase to achieve rapid spheroplasting. Low transformation efficiency in the present study might be due to handling errors, loss of viability of cells during plating, and the proportion of DNA and cells during transformation (Burgers and Percival, 1987).

\section{Lithium chloride method:}

In intact S. cerevisiae cells, monovalent cation $\mathrm{Li}+$ enhanced the transformation efficiency in the presence of PEG, and heat shock enhanced the transformation efficiency. Accordingly, we performed the transformation of P. pastoris GS115 with $5 \mu \mathrm{g}$ of pUSIXr. The transformants were selected on MD plates. The transformants appeared on the 2 nd or 
3rd day of incubation with an average transformation efficiency of $2 \times 103$. Ito et al. (1983) obtained the transformation efficiency of $4 \times 102$ using $1 \mu \mathrm{g}$ of DNA by treating the cells with lithium chloride. The procedure included plasmid DNA and polyethylene glycol (PEG), followed by a heat shock at $42{ }^{\circ} \mathrm{C}$.
Around 30 to $40 \%$ of competent cells take up one or more plasmid molecules, so the increase in plasmid concentration increases efficiency. Tsai et al.,(2017) obtained fewer transformants (20 $\mu \mathrm{g}$ of DNA) by following lithium acetate PEG mediated transformation methods. Comparatively, in the

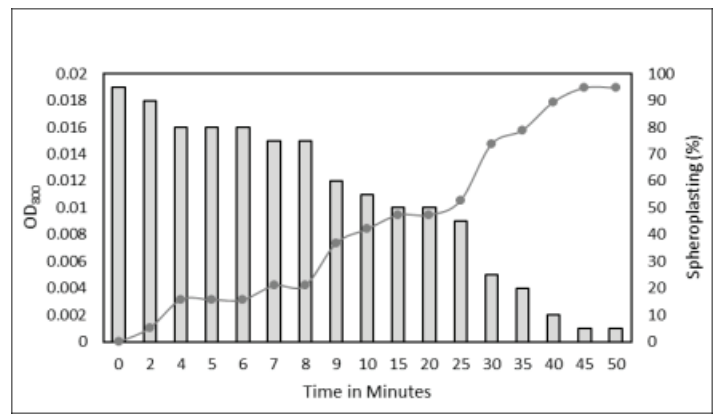

Figure 2. Generation of spheroplast using enzyme zymolyase: Spheroplasting was generated by incubating the cells after the addition of zymolyase and extending the time of incubation until the desired spheroplast was obtained.The OD800 (primary axis) denotes the measure of viable cells and the spheroplasting (\%) (secondary axis) increases with time is indicated.The optimal spheroplating (70\%) was obtained during 25 minutes of incubation with zymolyase.

present study, the lithium chloride method has given efficient transformation per $\mu \mathrm{g}$ pUSIXr.

\section{Electrophoration method:}

The Electrophoration method is a widely used efficient method for transformation. In our study, we used electrotransformation employing 1500 KV to $2000 \mathrm{KV}$ for $5 \mathrm{~ms}$ with $5 \mu \mathrm{g}$ pUSIXr. After giving the pulse, the cells were immediately chilled by the addition of $1 \mathrm{M}$ sorbitol followed by plating. The transformants were obtained on the 4th day of plating in RDB or MD. The transformation efficiency obtained was higher when compared with other methods of transformation. An average of $4 \times 105$ to $1 \times 106$ cells were obtained using this method (Wu and Letchworth, 2004) obtained 30-50 colony forming units (CFU) per microgram DNA at 2.5

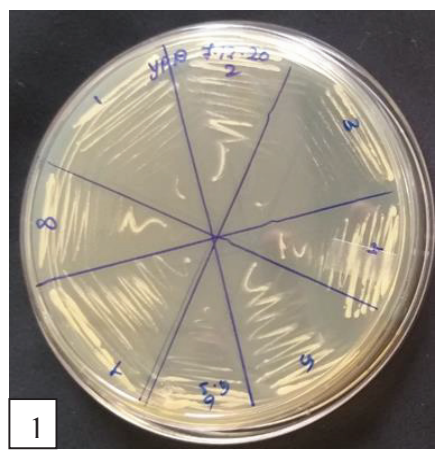

to $3.5 \mathrm{kv}$ for $4-5 \mathrm{~ms}$. The highest transformation efficiency in P. pastoris was obtained at $1.5 \mathrm{kV}, 25 \mu \mathrm{F}$, and $186 \Omega$ with $2.6 \times 105$ to $4 \times 106$ to per $\mu g$ DNA with pPIC9K. A maximum of $2.6 \times 105$ transformants was produced when $1 \mu \mathrm{g}$ of pPIC9K DNA was used (Wu and Letchworth, 2004).

\section{Transformation efficiency in P.pastoris GS115:}

Transformation of P. pastoris GS115 using spheroplast, $\mathrm{LiCl} 2$, and electroporation resulted in more recombinants in $\mathrm{LiCl} 2$ method followed by electroporation. The colonies appear in the selection plate after 2 to 3 days of incubation in lithium chloride method, and it took 4 to 6 days for electrophoration and spheroplast methods. The recombinants were confirmed by plating in RBD plate and control (Fig 3 ) and also by using a gene-specific

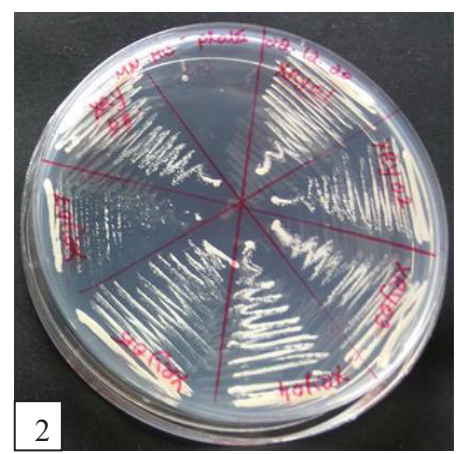

Figure 3: Representative transformants grown on YPD (1) and RDB (2) plate. P. pastoris GS115 wild type and transformants were streaked on YPD and RDB plates. The recombinants were able to synthesis His and were able to grow on RDB plate, whereas wild type P. pastoris GS115 did not grow on RDB plate. Both recombinants and wild type could grow on PDB control plate. The recombinants were positive for Xr gene amplification.

$107|10-12| 400$ 
primer PCR to confirm the integrated gene. Among the three methods, maximum transformants were obtained in the electroporation followed by lithium chloride for GS115, proving electroporation and $\mathrm{LiCl} 2$ as a method of choice suitable for transforming P. pastoris GS115.

\section{Acknowledgment}

Authors acknowledge the financial assistance from University Core Project (TNAU-Core ProjectCP016) to SU and Indo- Russia Joint collaboration supported by DBT, Gol, New Delhi (No.DBT/IC2/ Indo-Russia/2014-16/04) to SU. We are also thankful to DBT-BIOCARe (No. BT/PR18134/ $\mathrm{BIC} / 101 / 795 / 2016)$ for the grant awarderd to PR. The authors are grateful to the instrumentation facility extended by the metabolomics and proteomics analytical facility, Dept. of Agrl. Microbiology, TNAU, established under Gol-MHRD (FAST)-scheme.

\section{Author contributions:}

Research grant and Idea conceptualization, US; Experiments, PY; Guidance, US, RP Writing-original draft, PY; Writing- reviewing \&editing, US, RP

\section{REFERENCES}

Ahmad, M., M. Hirz, H. Pichler, and H. Schwab. 2014. "Protein expression in Pichia pastoris: recent achievements and perspectives for heterologous protein production."Applied Microbiology and Biotechnology 98(12): 5301-5317.

Ariyan, M., and Uthandi, S. 2019. "Xylitol Production by Xylose Reductase over producing Recombinant Escherichia coli M15."Madras Agric. J. 106 (13): 1 .

Burgers, P.M.J., and K.J. Percival. 1987. "Transformation of yeast spheroplasts without cell fusion." Analytical Biochemistry 163(2): 391-397.

Cereghino, J.L., and J.M. Cregg. 2000. "Heterologous protein expression in the methylotrophic yeast Pichia pastoris." FEMS Microbiology reviews 24(1): 45-66.
Cregg, J.M., K.J. Barringer, A.Y. Hessler, and K.R. Madden. 1985. "Pichia pastoris as a host system for transformations." Molecular and Cellular Biology 5(12): 3376-3385.

Hinnen, A.,J.B.Hicks, and G.R. Fink. 1978. "Transformation of yeast." Proceedings of the National Academy of Sciences 75(4): 1929-1933.

Ito, H., Y. Fukuda, K. Murata, and A. Kimura. 1983. "Transformation of intact yeast cells treated with alkali cations." Journal of Bacteriology 153(1): 163-168.

Jung, I.-Y., J.-W. Lee, W.-K. Min, Y.-C. Park, and J.-H. Seo. 2015. "Simultaneous conversion of glucose and xylose to 3-hydroxypropionic acid in engineered Escherichia coli by modulation of sugar transport and glycerol synthesis." Bioresource technology 198: 709-716.

Kawai, S.,W.Hashimoto, K. Murata. 2010. "Transformation of Saccaromyces cerevisiae and other fungi: methods and possible underlying mechanism." Bioeng Bugs 1(6): 395-403.

Lin-Cereghino, J., W.W. Wong, S. Xiong, W. Giang, L.T. Luong, J. Vu, S.D. Johnson, and G.P. LinCereghino. 2005. "Condensed protocol for competent cell preparation and transformation of the methylotrophic yeast Pichia pastoris." Biotechniques 38(1): 44-48.

Mohamad, N.L., S.M. Mustapa Kamal, and M.N. Mokhtar. 2015. "Xylitol biological production: a review of recent studies." Food reviews international 31(1): 74-89.

Orr-Weaver, T.L., J.W. Szostak, and R.J. Rothstein. 1981. "Yeast transformation: a model system for the study of recombination." Proceedings of the national Academy of Sciences 78(10): 6354-6358.

Tsai, Y.-Y., T. Ohashi, T. Kanazawa, P. Polburee, R. Misaki, S. Limtong, and K. Fujiyama. 2017. "Development of a sufficient and effective procedure for transformation of an oleaginous yeast, Rhodosporidium toruloides DMKU3-TK16." Current genetics 63(2): 359-371.

Wu, S., and G.J. Letchworth. 2004. "High efficiency transformation by electroporation of Pichia pastoris pretreated with lithium acetate and dithiothreitol." Biotechniques 36(1): 152-154 